The International Journal of Indian Psychology: Volume: 01 | Issue: 04 No. 2 | ISSN 2348-5396

\title{
Five Factor Model in Iranian Culture: A Psychometrics Analysis of NEO-Five Factor Inventory (NEO-FFI)
}

\author{
Manoochehr Azkhosh*, Ali Asgari**
}

\begin{abstract}
This study aimed to investigate the construct validity and factor structure of NEO-Five Factor Inventory (Costa \& McCrae, 1992) in Iranian population. Participants were 1639 (780 male, 859 female) Tehran people aged 15-71. The results of explanatory factor analysis showed no notable differences between the factor structures extracted by oblique and orthogonal rotations and didn't replicate the scoring key. The Openness and Agreeableness had more psychometric problems (low internal consistency and high deleted items). The female's NEO-FFI factor structure (with 41 items of60 loaded on intended factors)was clearer than males' (with 37 items). Confirmatory factor analysis supported the male's latent modeling of the 31-item but failed to fit the female's model. The women scored significantly higher in the Neuroticism, Openness, Agreeableness, and Conscientiousness than men who scored significantly higher in the Extraversion. As previous findings, the current results showed the NEO-FFI's cultural limitations assessing the universality of the Five Factor Model.
\end{abstract}

Keywords: Five Factor Model; NEO-FFI; Construct validity; Factor structure

\section{INTRODUCTION}

Psychological survey research is becoming ever concerned with the applicability of theoretical concepts across different cultures or nations and the importance of obtaining adequate measurements of those concepts for each of culture or nation (Welkenhuysen-Gybels, Billiet, and Cambre, 2003; Singelis et al., 2006).

In recent years, a massive body of psychological research and theorizing has focused on Five Factor Model of personality (FFM) and attention to this model has increased(Digman, 1990; Borkenauand Ostendorf, 1990; Goldberg, 1993). According to the model, there are five broad dimensions of personality (McCrae and Costa,1989; Digman, 1990)included Neuroticism, Extraversion, Openness to Experience, Agreeableness and Conscientiousness.

$* \& * *$, Professor, University of Social Welfare and Rehabilitation sciences, Iran All correspondences to Dr. Ali Asgari: asgarya@ut.ac.ir|azkhosh@uswr.ac.ir 
The International Journal of Indian Psychology: Volume: 01 | Issue: 04 No. 2 | ISSN 2348-5396

While, a several models have been developed based on the trait theory, to capture the main personality dimensions and interpret the individual differences (Eysenck, 1992, Cattell, 1950), the FFM has received widespread support and as Hofstede \& McCrae (2004) claimed contemporary personality psychology is dominated by the trait approach, in which individual differences in enduring dispositions are assessed.

In order to assess the FFM several instruments have been developed based on the theory (Borkenauand Ostendorf, 1989; McCrae, Costa \& Busch, 1986; Piedmont, McCrae, and Costa, 1991; Saucier, 1994; Sneed, McCrae, and Funder, 1998; John and Srivastava, 1999; Gosling, Rentfrowand Swann 2003), but the Five-Factor Inventory (NEO-FFI; Costa and McCrae, 1992), a brief 60-item version of the NEO-PI-R (Costa and McCrae, 1992), is an instrument that has been used ina variety of cultures, such as French (Rolland, Parker, and Stumpf, 1998), German (Borkenau and Ostendorf, 1993; Schmitz, Hartkamp, Baldini, Rollnik, and Tress, 2000), British (Egan, Deary, and Austin,2000), Poland, the Czech Republic and the Slovak Republic (Hrebícková et al., 2002), Greek (Panayiotou, Kokkinos and Spanoudis, 2004), Canada (Holden and Fekken, 1994;Becker, 2006), Austria (Fink, Manning andNeave, 2004), Australia (Sneed and et al., 2002; Gignac, Bates and Jang, 2007), Korea (Spirrisonand Choi, 1998),Indonesia (Halim, Derksenand van der Staak, 2004), Japan (Yoshimura, Ono, Nakamura, Nathan, and Suzuki, 2001), and Spain and Switzerland (Aluja, Garcıa, Rossier, and Garca, 2005).

In spite of its brevity, comprehensiveness, and ease of administration, that leads the NEO-FFI to a useful tool in clinical and research settings (Tokar, Fischer, Snell, and HarikWilliams, 1999) and receiving psychometric supports (Holden and Fekken (1994), many studies found some problematic criticisms (Sneed, Gullone, and Moore, 2002; Egan, Dearyand Austin, 2000).

\section{Big Five and factor analysis}

Although the NEO- FFI has found wide application indifferent cultures, several studies have shown that some of the items in this questionnaire are not applicable in many cultures. Because they are inconsistent with cultural, social and religious aspects of the specific cultures (Aluja, Rossier, Garcia, andVerardi, 2005; Garcia, Alujaand Garcia, 2004; Murray, Rawling, Nicholes, \& Trinder, 2008; McCraey and Costa, 2004). The results of exploratory factor analysis to assess the factor structure of the NEO in different cultures indicate that items of each factor will not be exactly repeated as the same items in the original one by Costa and McCray (1992).

In most studies of NEO-FFI's psychometric properties, (Panayiotou, Kokkinos and Spanoudis, 2004; Sneed, et al., 2002; Egan, Dearyand Austin, 2000; Ackerman and Heggestad, 1997; Tokar et al., 1999; Ferguson and Patterson, 1998; Yoshimura, et al.,2001)the construct validity have established by explanatory factor analysis found different results about 1) the number of items had loadings on their own factors, 2) the items had loadings larger than 0.3 or 0.4 on the other factors without salient secondary loadings on their appropriate factors, 3)the items had no loadings in any factors, 4) various reliability values and the percentages of variance was explained by the five factor, and finally 5 ) the possible factor solutions could be suggested 
Although these results can be due to some of reasons including sample variety (see Becker, 2006), variety of statistical methods such as using different factor analysis methods (e.g. principle component analysis vs. maximum likelihood) and orthogonal vs. oblique procedures (see McCrae and Costa,2004) and so on. But one of the most important reasons that can be explain these results, especially in non-speaking English language nations, have been rooted in cross-cultural studies problems (see Hofstedeand McCrae, 2004) that may be categorized in to methodological problems such as item translation and unrepresentative samples, and the problems related to the cultural dimensions such as different conceptualizations of the traits and their items in the nations, the cultures different response styles in different countries and different self-presentational motives, (see Hofstedeand McCrae, 2004;Huang, Church and Katigbak, 1997).

In the other hand, as researchers (Marsh et al. 2009, 2010; Holden and Fekken,1994; Borkenau and Ostendorf ,1990) argued many of measurement instruments factor structures (including NEO) that extracted and defined by EFA, are not confirmed and supported by CFA. Some authors (McCrae et al. ،1996) believed that the problem is rooted in the CFA itself when used to personality structure and some others (i.e. Church and Burke, 1994) pointed out the limitation caused by both personality theories and the CFA that are used to test the theories. But the problem can be also due to inconsistent between the traits and items that are loaded on them in a certain sample. Because of different definitions and conceptualizations of personality traits in different cultures, and various pattern of inter correlations between the traits it can be expected that original NEO-FFI model

\section{Big-five and Gender differences}

Several studies showed that there is a gender difference pattern of response in five personality factors. For example, women show higher scores regarding neuroticism, agreeableness, warmth (a facet of extraversion) and openness to feeling, while men show higher score for assertiveness (a facet of extraversion) and openness to idea on NEO (Costa, Terracciano \& McCrae, 2001). Replicating these findings in cross-cultural studies (McCrae, et al, 2005, Goodwin and Gotib, 2004) confirm the gender difference in the response to NEO's item. The pattern may be changed or reversed in different cultures, perhaps as a result of the different perception of trait indicators in women compared to men, or can be related to the measurement differences between these NEO-FFI items.

In addition, the pattern gender difference were not the same in several studies and showed the scores from low to moderate and some show in only some facets of the traits (Feingold, 1994). In regard of other factors men and women show little differences on either specific aspects of conscientiousness. Also many studies in regard of region in case of gender differences has shown that men in highly developed countries show less neuroticism, extraversion, conscientiousness and agreeableness than those men in less developed region, while women show no significance differences in personality traits regarding the region.
(C) 2014 www.ijip.in
July-September 2014
$80 \mid \mathrm{P}$ a g e 
As Schmitt etal. (2008) stated that the obtained results need to have more resources because these findings can be the result of low level of development in these countries, meanwhile it is seen that in these regions men may be more risk taking and social dominant while women are more cautious and nurturing. In addition, the amount and direction of gender differences depend on which aspect/aspects of personality or facets of a trait will be examined As March et al. (2001) argued the mean differences between men and women that evidently lies in latent traits, in fact, reflect the difference in the items. Thus, if gender differences in extraversion and agreeableness vary substantially from item to item, the corresponding construct of those items which are used to infer extraversion can be different between genders, too.

Clearly, one of the difficulties facing researchers wishing to investigate psychological constructs across cultures has been validation of the measures. One cannot readily assume that measurement instruments developed in one culture can be used and compared in the same manner with another one. The comparability of scores across cultural contexts depends on their validity and equivalence level (Huiand Triandis, 1985; Berry, 1989; van de Vijverand Leung, 1997). Thus establishing construct validity is an important part of instrument validation. Especially in the intercultural research when an instrument is to measures the same construct across different cultures.

The main purpose of this research is to investigate the factor structure of the Persian version of NEO-FFI, and to study the concepts of the instrument based upon the Five Factor Model. The growing use of FFM theory and instruments in Persian speaking countries makes it both a theoretical and practical imperative to validate its concepts and tools within this unique context. Clearly, one of the most fundamental tasks of any theory is to clearly identify the concepts that make up the theory. Furthermore, because of the many studies (e.g. Digman, 1997; Deary et al., 1996; Block, 1995) showed there are high correlations between the five factors, despite the assumption that the factors are independence (Costa and McCrae, Hofstee, 2003; Costa and McCrae, 1992; Goldberg, 1993), another purpose is comparing the results of factor analysis based on orthogonal and oblique rotations in order to find the best Persian NEO-FFI factor structure.

\section{METHOD}

\section{Participants and procedure}

A large sample of1639(780 male, 859 female) member of Tehran community, aged 15-71 years, were selected randomly using multiple sampling method of schools, universities, state and private organizations, public places, etc. Demographic characteristics of the sample groups has displayed in Table 1. The self-report were administrated by 30 post graduate students in clinical psychology and counseling, as examiners and completed by participants individually.

\section{Table 1}

Demographic characteristics of the samples

\begin{tabular}{|l|l|l|}
\hline variable & Male & female \\
\hline Size & & \\
\hline
\end{tabular}


The International Journal of Indian Psychology: Volume: 01 | Issue: 04 No. 2 | ISSN 2348-5396

\begin{tabular}{|l|l|l|}
\hline $\mathrm{n}$ & 780 & 859 \\
\hline$\%$ & 48.6 & 51.4 \\
\hline Marriage status & & \\
\hline single & 341 & 455 \\
\hline married & 439 & 404 \\
\hline Education & & \\
\hline High school & 346 & 344 \\
\hline B.A & 361 & 485 \\
\hline M.A & 61 & 22 \\
\hline Age & & \\
\hline M & 32.0 & 28.2 \\
\hline SD & 11.5 & 10.3 \\
\hline
\end{tabular}

\section{MATERIAL}

The Persian translation of the NEO Five-Factor Inventory(NEO-FFI; Costa and McCrae, 1992) was used to assess the Big Five, included Neuroticism (N), Extraversion (E), Openness to experience (O), Agreeableness (A), and Conscientiousness (C. Each scale has 12 items and is scored on a five-point Liker response format.

The adaptation NEO-FFI was done using the back translation method which is a judgmental procedure for investigating the conceptual equivalence of the original and translated versions necessary for valid cross-cultural comparisons (Brislin, 2000). First, three different specialists who were fluent in both Persian and English (bilingual translator, clinical psychologist and psychometric an) translated the NEO-FFI into Persian. Second, three other specialists in the same fields and who were fluent in both languages were randomly assigned to one of the Persian versions, translated the Persian versions back into English. Third, the original source and back translated items were compared for non-equivalence of meaning and any discrepancies were noted by experts who were bi-lingual. Finally, the resulting version was administered on a sample of 100(60 female and 40 male)I $n$ order to identify ambiguous or confusing items. The ambitious words marked by the majority of students were replaced.

\section{Data analysis}

The analysis conducted in three phases. In the first, to test of fitness the NEO-FFI original structure to Iranian sample, a confirmatory factor analysis (CFA) was done. In the second, to explore the factor structure of the Persian NEO-FFI an explanatory principle component analysis (PCA) was performed, using both orthogonal (i.e. varimax) and oblique (i.e. oblimin) rotations for male and female separately. Several studies (Panayiotou, et al., 2004; Sneed et al., 1998; Egen, Deary, and Austin, 2000) have been conducted by combining the two rotations, which enable depth understanding the factor structure of the instrument.In the third phase, a confirmatory second-order factor analysis (CFA) was conducted using LISREL (Jöreskog and Sörbom, 2003) to test the models developed based on the results of PCA. 
The International Journal of Indian Psychology: Volume: 01 | Issue: 04 No. 2 | ISSN 2348-5396

\section{RESULTS}

\section{Descriptive statistics}

Descriptive statistics and Kolmogorov -Smirnov (K-S) test of normality of the Big Five factors for male and female are showed in Table 2. All of the distributions were skewed significantly and had identical pattern in both groups. The Neuroticism score distribution was positively and the other factors were negatively skewed. The $\alpha$-coefficients for the Openness to Experience and Agreeableness were low for the groups and present evidence for inadequate internal consistency of the two factors. But these coefficients were good for the Neuroticism, Extraversion and Conscientiousness factors.

The means of the factors for the male and female groups were compared by t-test. The result showed significant mean differences for Neuroticism $(t=5.28, p<.01)$, Extraversion $(t=$ 4.12, $\mathrm{p}<.01)$, Openness to Experience $(\mathrm{t}=3.96, \mathrm{p}<.01)$, Agreeableness, and $(\mathrm{t}=2.91$, $\mathrm{p}<.01)$, conscientiousness $(\mathrm{t}=2.23, \mathrm{p}<.05)$. Thus, the women had higher scores in the Neuroticism, Openness to Experience, Agreeableness, and Conscientiousness than men, whereas the men had higher score in the Extraversion. Considering the mean differences between male and female sample, the following statistical analysis was conducted separately.

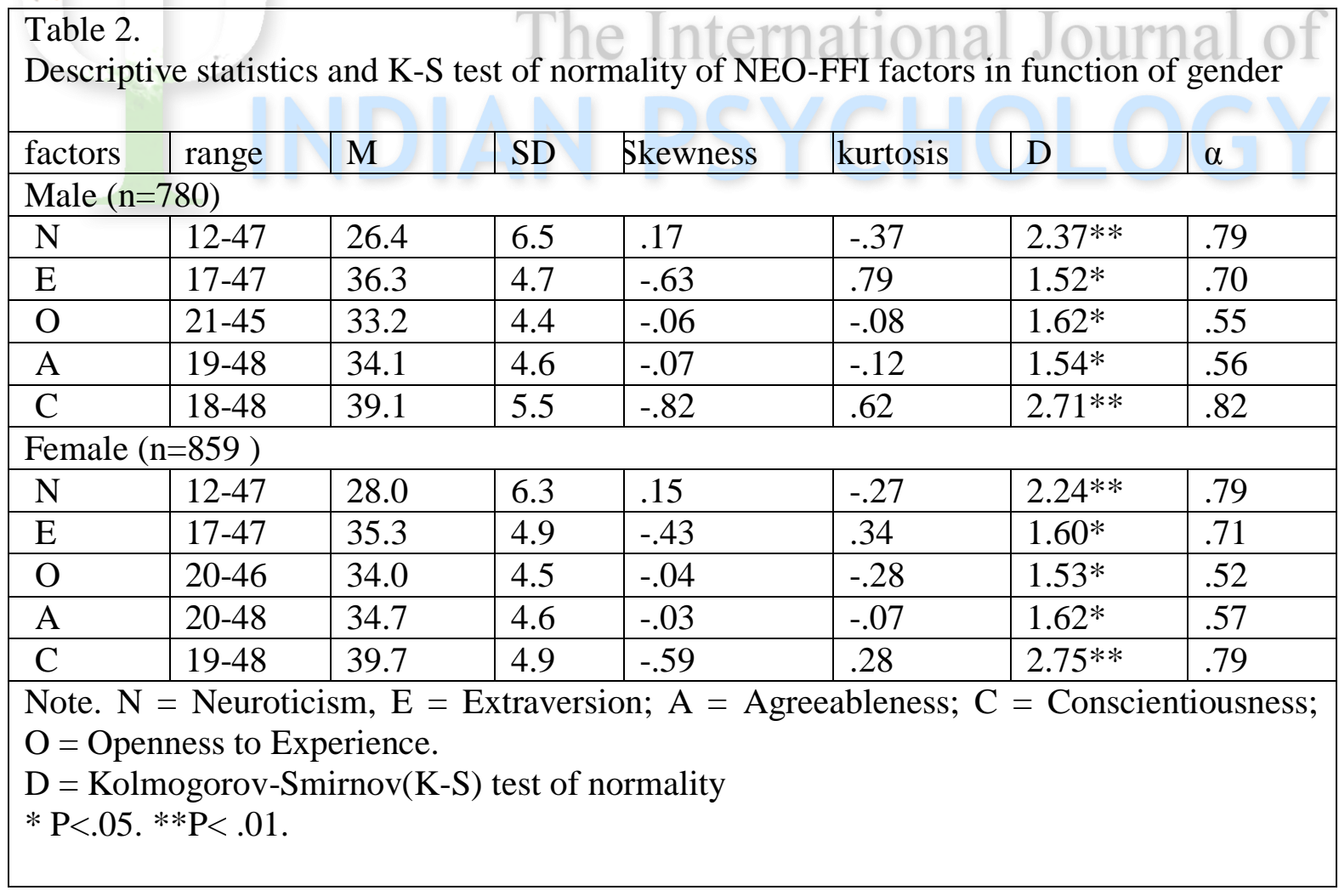


The International Journal of Indian Psychology: Volume: 01 | Issue: 04 No. 2 | ISSN 2348-5396

\section{Test of the NEO original factor structure}

Two CFA models (one for men and one for women) were developed for confirming the original factor structure of NEO-FFI based on Persian Sample. This analysis was conducted to ascertain the extent to which the 5-factor model would demonstrate a fit to Iranian culture.

As indicated in Table 3, both models provided a poor fit to these data.

\section{Table 3}

The Goodness of Fit Statistics for CFA Models of Persian NEO-FFI based on original factor structure

\begin{tabular}{|c|l|l|l|l|l|l|l|}
\hline Models & $\chi^{2}$ & df & $\chi^{2} /$ df & GFI & IFI & CFI & RMSEA \\
\hline Male & $6611.96^{* *}$ & 1700 & 3.89 & .69 & .84 & .84 & .055 \\
\hline Female & $5621.55^{* *}$ & 1700 & 3.30 & .72 & .86 & .86 & .054 \\
\hline
\end{tabular}

Note. GFI=goodness of fit index, IFI= Incremental Fit Index, CFI=Comparative Fit Index, RMSEA=Root Mean Square Error of Approximation.

$* * \mathrm{P}<.001$.

\section{Exploratory factor analysis}

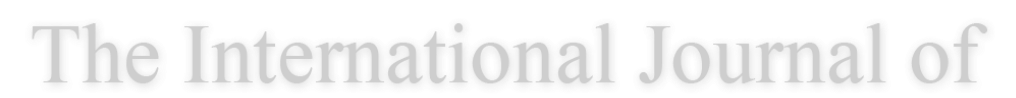

An examination of model fit statistics revealed the five-factor model didn't fit the data well according to the significant chi-square index, the relative chi-square (per degrees of freedom $>$ 2.0; Byrne 1989), and the RMSEA that was higher than .05 (indicating good fit $\mathrm{Hu}$ and Bentler, 1999; Browne and Cudeck, 1993). On the other hand, the goodness-of-fit indices for this model including CFI, GFI, and IFI were lower than 0.9, indicating less than acceptable model fit. Taken together, these results suggest that NEO original factor structure does not provide a good fit to these the data and an exploratory principle component analysis (PCA) should be used to provide guidance regarding factor loadings of NEO items and provided a suggested model for subsequent analyses.

In order to explore the factor structure of NEO-FFI in the Iranian population, a principle component analysis (PCA) of the 60 items were conducted using orthogonal and oblique rotations for male and female separately. In the male sample, the Kaiser-Meyer-Olkin (KMO) measure of sampling adequacy was .87, and the Bartlett's Test of Sphericity (BTS), Approx. Chi-Square $=10954.94(\mathrm{df}=1770, \mathrm{p}<.001)$. For the female sample, the indexes were.86 and1152.61 ( $\mathrm{df}=1770, \mathrm{p}<.001)$ respectively. The screed plots of both models shown in Figure 1 .

The communality, eigenvalues, explained variance and factor loadings for orthogonally and obliquely rotated five factors for men and women showed in Table 4 and 5, respectively. As table 4 indicated, in male sample, there are some discrepancies between the present results and the factors of inventory's scoring key. In both varimax and oblimin rotations 37 items of the 60
(C) 2014 www.ijip.in
July-September 2014
$84 \mid \mathrm{P}$ a g e 
items belonged to their appropriate factors. Furthermore, 10 items in the varimax and 9 items in the obliminrotation had no factor loadings. The items of E52, O8, E22, A49, A4, O38 (in varimax) and $\mathrm{O} 3$ (in oblimin) were loaded on factor 1 that corresponded to Conscientiousness. In factor 2, Neuroticism, 9 items were the same with the NEO-FFI manual. Items C30 and C45 had higher loadings on the Neuroticism than the Conscientiousness.

Factor 3, compared with Extraversion, has 7 of the 12 items belonged to their appropriate factor. Items N46 and A33were loaded only in the factor. In obliminrotationE32 and E37had factor loadings higher than .30 in the Conscientiousness. There are some discrepancies between the two rotation methods in the case of Openness to Experience. It is the forth factor in oblimin and fifth factor in varimax procedure and only 6 of its 12 items belonged to the related factor. Items $\mathrm{O} 53$ and O58were loaded only in the Agreeableness. In oblimin rotation item O53was loaded on the Conscientiousness and Extraversion with equal loadings relatively. Finally, the Agreeableness had 6 of 12 items corresponded to the NEO-FFI key scoring. The item of E27 is loaded only in this factor.
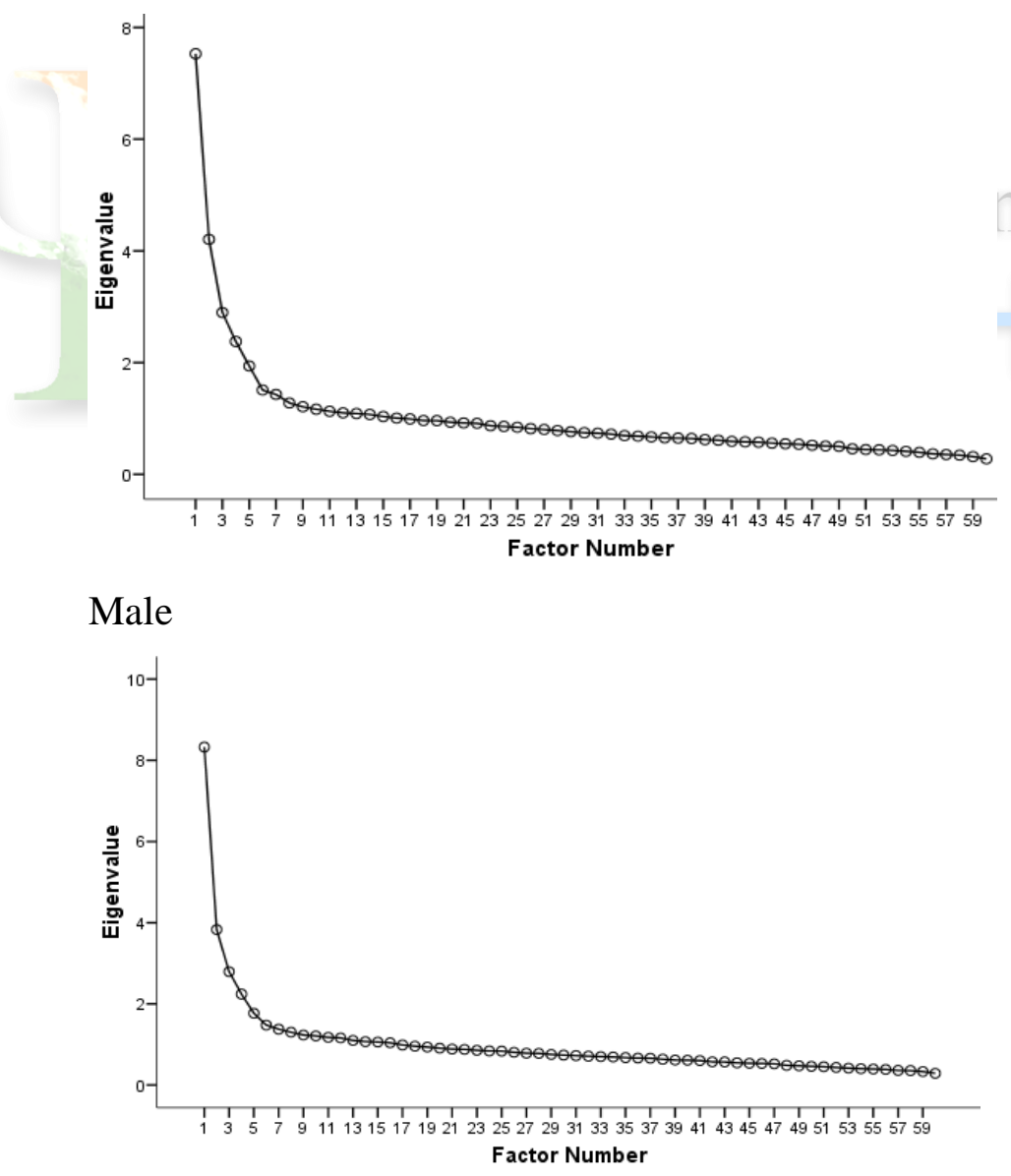

Female

Figure 1. The screed plot for male and female groups 
The International Journal of Indian Psychology: Volume: 01 | Issue: 04 No. 2 | ISSN 2348-5396

Table 4

Factor loadings, communalities, eigen values and percentages of variance from PCA using varimax and oblimin rotation for five factor solution of Iranian NEO-FFI (male sample)

\begin{tabular}{|c|c|c|c|c|c|c|c|c|c|c|c|c|c|}
\hline & vari & hax & & & & & & oblim & & & & & \\
\hline $\begin{array}{l}\text { Item } \\
\mathrm{s}\end{array}$ & $\mathrm{C}$ & $\mathrm{N}$ & $\mathrm{E}$ & A & $\mathrm{O}$ & & Items & $\mathrm{C}$ & $\mathrm{N}$ & $\mathrm{E}$ & $\mathrm{O}$ & A & $h^{2}$ \\
\hline C15 & $\begin{array}{l}.67 \\
7\end{array}$ & & & & & & C15 & .679 & & & & & .48 \\
\hline C35 & $\begin{array}{l}.65 \\
7\end{array}$ & & & & & & C35 & .671 & & & & & .51 \\
\hline $\mathrm{C25}$ & $\begin{array}{l}\mathbf{5 8} \\
9\end{array}$ & & & & & & $\mathrm{C25}$ & .610 & & & & & .40 \\
\hline C5 & $\begin{array}{l}\mathbf{5 8} \\
\mathbf{3}\end{array}$ & & & & & & C60 & .597 & & & & & .38 \\
\hline C50 & $\begin{array}{l}.57 \\
6\end{array}$ & & & & & & C50 & .593 & & & & & .41 \\
\hline C60 & $\begin{array}{l}.57 \\
0\end{array}$ & & $\mathrm{TM}$ & & & & C5 & .571 & & & & & .37 \\
\hline C10 & $\begin{array}{l}.55 \\
2\end{array}$ & & & & & & C10 & .566 & & nal & & & .34 \\
\hline $\mathrm{C20}$ & $\begin{array}{l}.54 \\
2 \\
\end{array}$ & & & & & . & E52 & .552 & $P_{2}$ & -.403 & & & .46 \\
\hline E52 & $\begin{array}{l}.51 \\
7 \\
\end{array}$ & 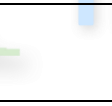 & $\begin{array}{l}.31 \\
7\end{array}$ & & 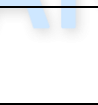 & 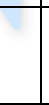 & $\mathrm{C20}$ & .548 & | & 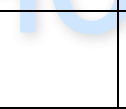 & 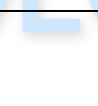 & & .35 \\
\hline $\mathrm{C40}$ & $\begin{array}{l}.50 \\
4\end{array}$ & & & & & & O8 & .522 & & & & & .33 \\
\hline O8 & $\begin{array}{l}.50 \\
1 \\
\end{array}$ & & & & & & C40 & .520 & & & & & .29 \\
\hline E22 & $\begin{array}{l}.46 \\
6 \\
\end{array}$ & & & & & & C55 & .491 & -.414 & & & & .39 \\
\hline C55 & $\begin{array}{l}.45 \\
4 \\
\end{array}$ & -.425 & & & & & E22 & .478 & & & & & .24 \\
\hline A49 & $\begin{array}{l}.43 \\
3\end{array}$ & & & & & & A49 & .450 & & & & & .25 \\
\hline A4 & $\begin{array}{l}.42 \\
8\end{array}$ & & & & & & A4 & .447 & & & .309 & & .36 \\
\hline O38 & .307 & & & & & & O38 & -.302 & & & & & .21 \\
\hline O3 &. & & & & & & O3 & & & & & & .12 \\
\hline N51 & & .661 & & & & & N51 & & $\begin{array}{l}.65 \\
8 \\
\end{array}$ & & & & .49 \\
\hline
\end{tabular}


The International Journal of Indian Psychology: Volume: 01 | Issue: 04 No. 2 | ISSN 2348-5396

\begin{tabular}{|c|c|c|c|c|c|c|c|c|c|c|c|c|}
\hline N56 & & .592 & & & & N11 & & \begin{tabular}{|l|}
.59 \\
8
\end{tabular} & & & & .39 \\
\hline N11 & & \begin{tabular}{|l|}
.587 \\
\end{tabular} & & & & N56 & & \begin{tabular}{|l|}
.59 \\
$\mathbf{3}$
\end{tabular} & & & & .41 \\
\hline N41 & & .563 & & & & N41 & & \begin{tabular}{|l|}
.55 \\
3
\end{tabular} & & & & .37 \\
\hline N26 & & .532 & & & & N26 & & \begin{tabular}{|l|}
.54 \\
5
\end{tabular} & & & & .42 \\
\hline N1 & & .523 & -.302 & & & N1 & & \begin{tabular}{|l|}
.54 \\
1
\end{tabular} & .326 & & & .41 \\
\hline N36 & & .512 & & & & $\mathbf{N 2 1}$ & & \begin{tabular}{|l|}
.53 \\
1
\end{tabular} & .358 & & -.370 & .47 \\
\hline $\mathbf{N} 21$ & & .507 & -.324 & -.330 & & N36 & & \begin{tabular}{|l|}
.52 \\
$\mathbf{3}$
\end{tabular} & & & & .33 \\
\hline $\mathrm{C} 45$ & $\begin{array}{l}.32 \\
4\end{array}$ & -.434 & & & & N6 & & \begin{tabular}{|l|}
.42 \\
8
\end{tabular} & & & & .26 \\
\hline N6 & & .422 & & & & C45 & .354 & -.427 & & & & .19 \\
\hline C30 & $\begin{array}{l}.32 \\
9\end{array}$ & -.405 & & & & C30 & .333 & -.403 & & & & .28 \\
\hline$A 38$ & & & IM & & & $A 38$ & & & & & & .19 \\
\hline N31 & & & & & & N31 & & & & & & .09 \\
\hline$E 47$ & & & & & & E47 & & & & & & .11 \\
\hline$E 57$ & & & & & & E57 & erins & 1010 & nat & $\sqrt{04}$ & ina & .04 \\
\hline E37 & 8 & & $\begin{array}{l}.75 \\
0\end{array}$ & & & E37 & .325 & 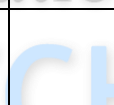 & -.781 & & & .65 \\
\hline E12 & & & $\begin{array}{l}.68 \\
4\end{array}$ & 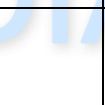 & $1+1$ & E12 & tra & 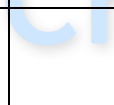 &.- .717 & 2 & 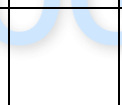 & .56 \\
\hline $\mathbf{E 4 2}$ & & & $\begin{array}{l}.68 \\
2\end{array}$ & & & E42 & & & -.715 & & & .54 \\
\hline $\mathbf{E 3 2}$ & & & $\begin{array}{l}.57 \\
1\end{array}$ & & & E32 & .365 & &.- .621 & & & .47 \\
\hline E7 & & & $\begin{array}{l}.54 \\
2\end{array}$ & & & E7 & & &.- .543 & & & .32 \\
\hline E17 & & & $\begin{array}{l}.47 \\
6\end{array}$ & & & E17 & & & \begin{tabular}{|l|}
-.508 \\
\end{tabular} & & & .34 \\
\hline $\mathrm{N} 46$ & & & -.457 & & & N46 & & & .456 & & & .29 \\
\hline & & & & & & \multicolumn{7}{|c|}{ (Table 4 continues) } \\
\hline
\end{tabular}

\begin{tabular}{|l|l|l|l|l|l|l|l|l|l|l|l|l|l|l|}
\hline \multicolumn{10}{|c|}{ (Table 4 continued) } \\
\hline \multicolumn{10}{|c|}{ varimax } \\
\hline Items & $\mathrm{C}$ & $\mathrm{N}$ & $\mathrm{E}$ & $\mathrm{A}$ & $\mathrm{O}$ & & Items & $\mathrm{C}$ & $\mathrm{N}$ & $\mathrm{E}$ & $\mathrm{O}$ & $\mathrm{A}$ & $\mathrm{h}^{2}$ \\
\hline E2 & & & $\begin{array}{l}\mathbf{. 4 0} \\
\mathbf{8}\end{array}$ & & & & A33 & & & -.397 & & & .18 \\
\hline
\end{tabular}


The International Journal of Indian Psychology: Volume: 01 | Issue: 04 No. 2 | ISSN 2348-5396

\begin{tabular}{|c|c|c|c|c|c|c|c|c|c|c|c|c|}
\hline A33 & & & $\begin{array}{l}.36 \\
7\end{array}$ & & & E2 & & & -.389 & & & .21 \\
\hline N16 & & & & & & N16 & & & & & & .14 \\
\hline 028 & & & & & & $O 28$ & & & & & & .08 \\
\hline A14 & & & & .558 & & $\mathbf{O 4 3}$ & & & & .634 & & .47 \\
\hline O58 & & & & .477 & & $\mathbf{O 2 3}$ & & & & .601 & & .38 \\
\hline A9 & & & & .454 & & O48 & & & & .497 & & .37 \\
\hline A24 & & & & .423 & & $\mathbf{O 3}$ & $\begin{array}{l}.35 \\
4\end{array}$ & & -.333 & .469 & & .37 \\
\hline A54 & & & & .416 & & $\mathbf{O 3 3}$ & & & & .447 & & .22 \\
\hline O53 & & & & .393 & & A19 & & & & .308 & & .18 \\
\hline A44 & & & & .363 & & 018 & & & & & & .09 \\
\hline A29 & & & & .316 & & A14 & & & & & .561 & .38 \\
\hline$E 27$ & & & & & & A9 & & & & & .484 & .31 \\
\hline A59 & & & & & & O58 & & & & & -.465 & .27 \\
\hline $\mathbf{O 4 3}$ & & & & & $\begin{array}{l}.63 \\
1\end{array}$ & A24 & & & & & .455 & .29 \\
\hline $\mathbf{O 2 3}$ & & & & & $\begin{array}{l}60 \\
6 \\
\end{array}$ & A54 & & & & & .428 & .21 \\
\hline $\mathbf{O 4 8}$ & & & TM & & $\begin{array}{l}.48 \\
1\end{array}$ & A44 & & & & & .387 & .23 \\
\hline $\mathbf{O 3}$ & $\begin{array}{l}.30 \\
5\end{array}$ & & & & $\begin{array}{l}44 \\
9\end{array}$ & O53 & .32 & tion & â3 & Oull & $\begin{array}{l}-.367 \\
12 a 1 \\
\end{array}$ & .37 \\
\hline $\mathbf{O 3 3}$ & & & & & $\begin{array}{l}.43 \\
3\end{array}$ & A29 & $\sqrt{2}$ & 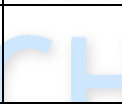 & & & .341 & .18 \\
\hline$A 19$ & T & 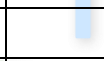 & $\nabla$ & 4 & 21 & E27 & 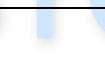 & $\theta$ & 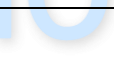 & $+y$ & .315 & .19 \\
\hline 018 & & & & & & A59 & & & & & & .11 \\
\hline $\begin{array}{l}\text { Eigenvalu } \\
\mathrm{e}\end{array}$ & $\begin{array}{l}8.3 \\
2\end{array}$ & \begin{tabular}{|l|}
3.8 \\
2 \\
\end{tabular} & $\begin{array}{l}2.7 \\
9\end{array}$ & 2.24 & $\begin{array}{l}1.7 \\
7\end{array}$ & & & & & & & \\
\hline$\%$ variance & $\begin{array}{l}13 . \\
9\end{array}$ & 6.39 & $\begin{array}{l}4.6 \\
6\end{array}$ & 3.74 & $\begin{array}{l}2.9 \\
5\end{array}$ & & & & & & & \\
\hline
\end{tabular}

Note: Boldface indicates items belonged to the appropriate factors. Italic indicates items have no factor loadings.

Factor loading $>0.3$.

$\mathrm{C}=$ Conscientiousness, $\mathrm{N}=$ Neuroticism, $\mathrm{E}=$ Extraversion, $\mathrm{O}=$ Openness to Experience, $\mathrm{A}=$ Agreeableness. $\mathrm{h}^{2}=$ communality (ordered based on the items column of the oblimin procedure).

Factor structure of NEO-FFI in the female sample (Table 5) is relatively clearer than male's. The items belonged to their appropriate factors are more (41 items) and the items that have no loadings on the any factor are less than male sample. The Conscientiousness is the first factor which has 16 items but only 10 items are the same with NEO-FFI manual. Like the male sample, the items of O8, O38, A4, A49, E22 and E52 are loaded on this factor. Agreeableness, the second factor in the oblimin procedure and the fifth in the varimax procedure, has 7 items
(C) 2014 www.ijip.in
July-September 2014
$88 \mid \mathrm{P}$ a g e 
The International Journal of Indian Psychology: Volume: 01 | Issue: 04 No. 2 | ISSN 2348-5396

that was corresponded to the appropriate factor. The items that were loaded on Extraversion are 10 and 11 in the varimax and oblimin procedures, respectively, and only 7 items belonged to original inventory. The items that are loaded on this factor have no loading in the other factors. Neuroticism is the third factor in varimax and fifth factor in oblimin procedure and has 9 of 12 main items. Openness to Experience is the fourth factor in both rotations. All of the 8 items which loaded on this factor belonged to the appropriate factor.

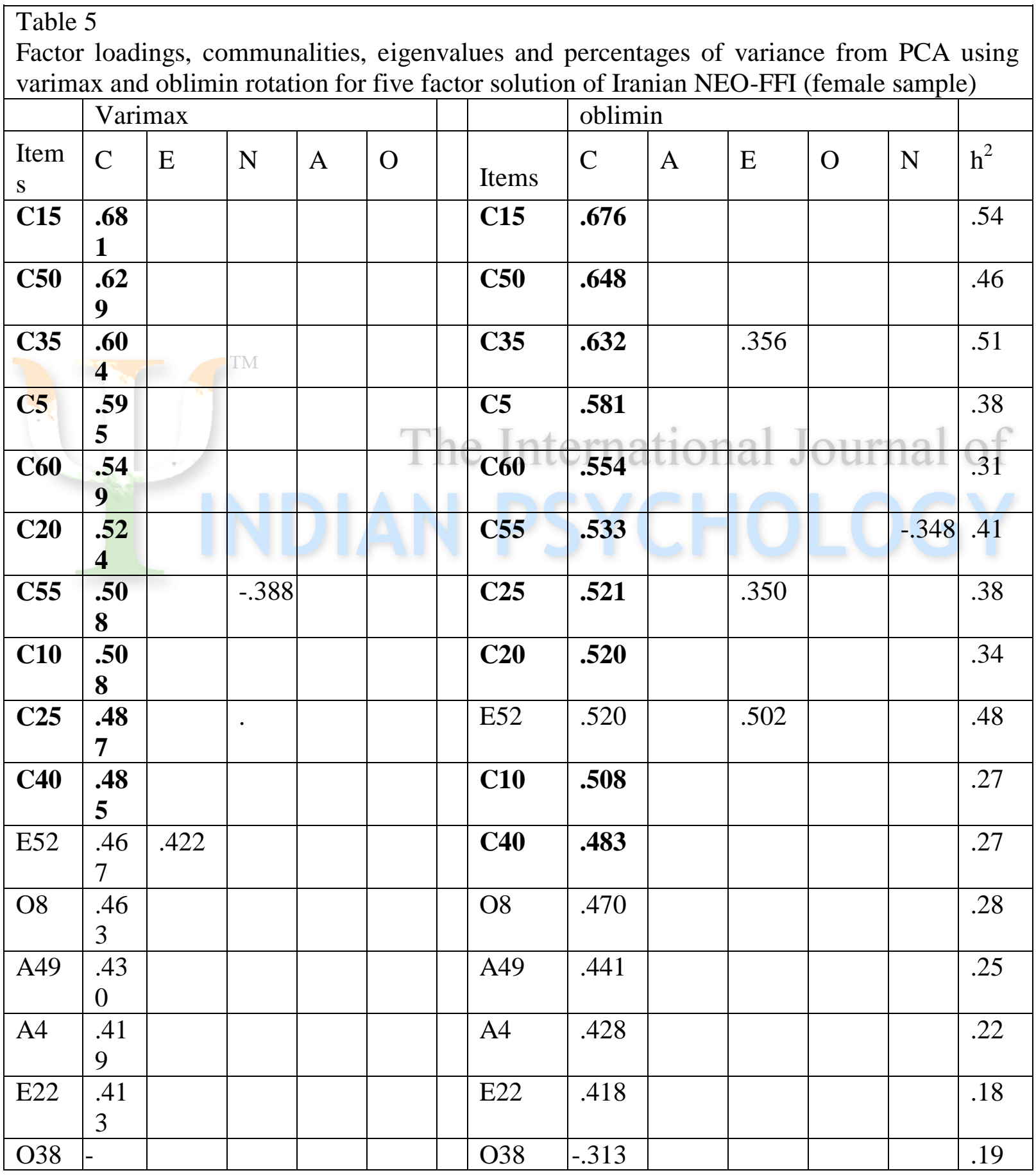


The International Journal of Indian Psychology: Volume: 01 | Issue: 04 No. 2 | ISSN 2348-5396

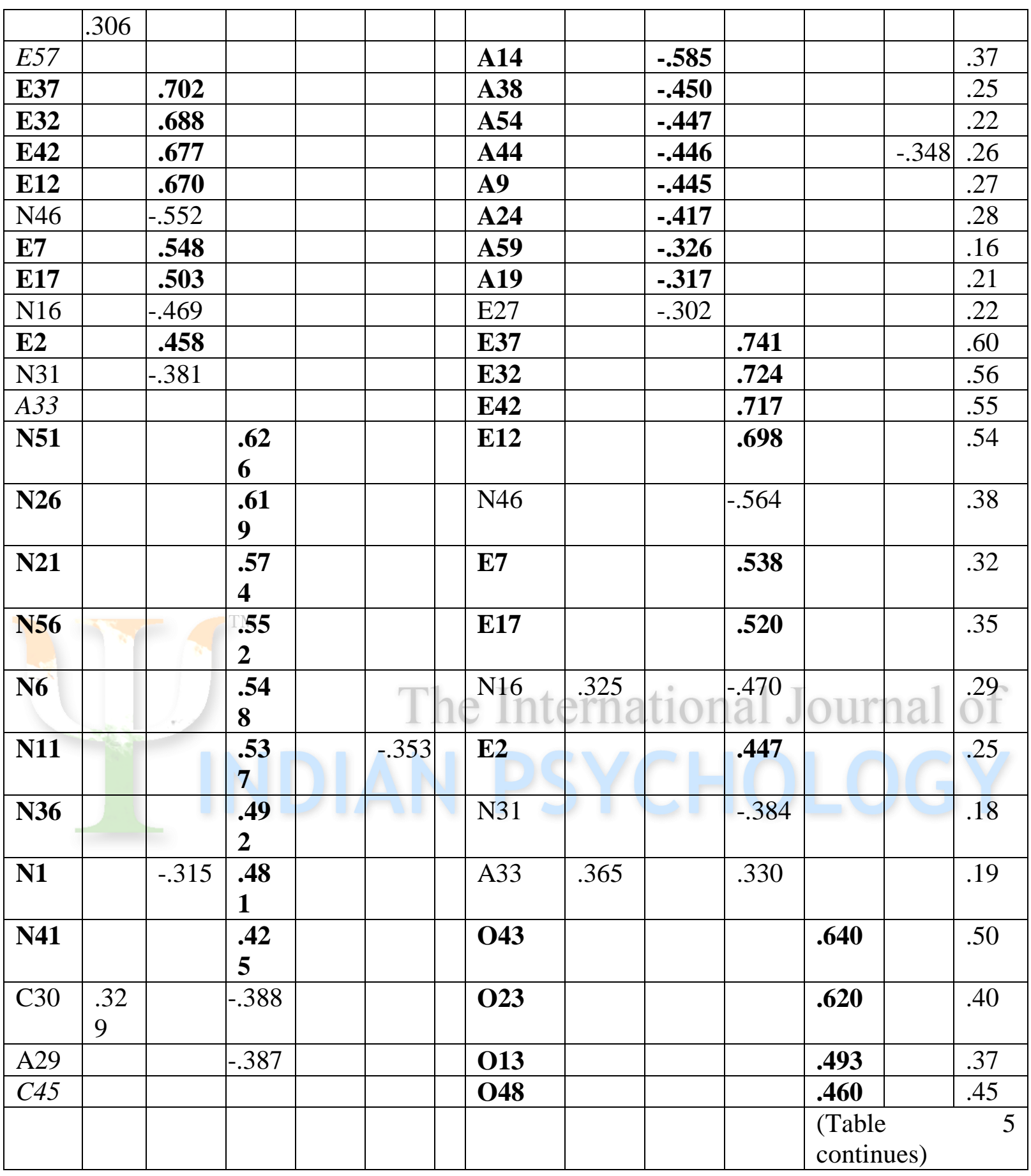

\begin{tabular}{|l|l|l|l|l|l|l|l|l|l|l|l|l|l|}
\hline \multicolumn{10}{|c|}{ (Table 5 continued) } \\
\hline \multicolumn{10}{|l|}{ varimax } \\
\hline Items & C & E & N & A & O & Items & C & A & E & O & N & $\mathrm{h}^{2}$ \\
\hline E177 & & & & & & $\mathbf{O 3 3}$ & & & & $\mathbf{. 3 9 4}$ & & .21 \\
\hline O43 & & & & $\mathbf{. 6 3 8}$ & & $\mathbf{O 5 3}$ & & .308 & & $\mathbf{. 3 9 1}$ & & .37 \\
\hline $\mathbf{O 2 3}$ & & & & $\mathbf{. 6 1 2}$ & & $\mathbf{O 2 8}$ & & & & $\mathbf{. 3 7 1}$ & & .17 \\
\hline
\end{tabular}


The International Journal of Indian Psychology: Volume: 01 | Issue: 04 No. 2 | ISSN 2348-5396

\begin{tabular}{|c|c|c|c|c|c|c|c|c|c|c|c|c|}
\hline 013 & & & & .480 & & 058 & & & & .331 & & .24 \\
\hline 048 & & & & .440 & & 018 & & & & & & .11 \\
\hline 053 & & & & .396 & -.396 & $\mathrm{O} 3$ & & & & & .609 & .12 \\
\hline $\mathbf{0 3 3}$ & & & & .388 & & N51 & & & & & .608 & .45 \\
\hline $\mathbf{0 2 8}$ & & & & .368 & & $\mathrm{~N} 26$ & & & -.304 & & .568 & .45 \\
\hline 058 & & & & .354 & & N21 & & .363 & & & .540 & .44 \\
\hline 018 & & & & & & N11 & & & & & .537 & .33 \\
\hline O3 & & & & & & N56 & & & & & .533 & .34 \\
\hline A14 & & & & & $\begin{array}{l}.56 \\
7\end{array}$ & N6 & & & & & .490 & .34 \\
\hline A44 & & & & & $\begin{array}{l}.44 \\
6\end{array}$ & N36 & & .416 & & & .490 & .38 \\
\hline A54 & & & & & $\begin{array}{l}.43 \\
8 \\
\end{array}$ & N1 & & & -.331 & & .415 & .36 \\
\hline A38 & & & & & $\begin{array}{l}.43 \\
8 \\
\end{array}$ & N41 & & & & & -.389 & .24 \\
\hline A9 & & & & & $\begin{array}{l}.39 \\
5\end{array}$ & A29 & & & & & -.359 & .18 \\
\hline A24 & & & $\mathrm{TM}$ & & $\begin{array}{l}.36 \\
6\end{array}$ & $\mathrm{C} 30$ & $\begin{array}{l}.35 \\
5 \\
\end{array}$ & & & & .609 & .28 \\
\hline A19 & & & -.357 & & \begin{tabular}{l|l}
.33 \\
0
\end{tabular} & $C 45$ & & 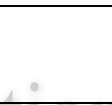 & & & & .19 \\
\hline$E 27$ & & 2 & & & 11 & E47 & 111d & 0101 & ald Ju & OUI & $1 d 1$ & .11 \\
\hline$A 59$ & & & & & & E57 & & & & & 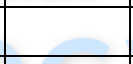 & .06 \\
\hline & & & & & & 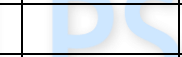 & 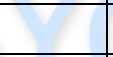 & & 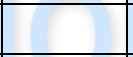 & & + & $r$ \\
\hline $\begin{array}{l}\text { Eigenvalu } \\
\mathrm{e}\end{array}$ & $\begin{array}{l}7.5 \\
3 \\
\end{array}$ & $\begin{array}{l}4.2 \\
1 \\
\end{array}$ & $\begin{array}{l}2.8 \\
9 \\
\end{array}$ & 2.38 & $\begin{array}{l}1.9 \\
4\end{array}$ & +2 & 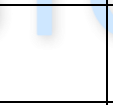 & $x_{1}$ & the & -1 & 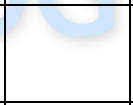 & 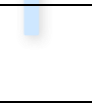 \\
\hline$\%$ variance & $\begin{array}{l}12 . \\
5\end{array}$ & 7.01 & $\begin{array}{l}4.8 \\
3 \\
\end{array}$ & 3.96 & $\begin{array}{l}3.2 \\
3 \\
\end{array}$ & & & & & & & \\
\hline \multicolumn{13}{|c|}{$\begin{array}{l}\text { Note: Boldface indicates items belonged to the appropriate factors. Italic indicates items have no } \\
\text { factor loadings. } \\
\text { Factor loading }>0.3 \text {. } \\
\mathrm{C}=\text { Conscientiousness, N=Neuroticism, E=Extraversion, } \mathrm{O}=\text { Openness to Experience, } \\
\mathrm{A}=\text { Agreeableness. } \\
\mathrm{h}^{2}=\text { communality (ordered based on the items column of the oblimin procedure). }\end{array}$} \\
\hline
\end{tabular}

The results of explanatory factor analysis indicated that a few items had loadings on one of the other factors. As shown in Table 6 most of these items were loaded on the Conscientiousness and are relatively the same in the two groups. Items of E5 "I like to be where the action is", O2 "Once I find the right way to do something, I stick to it", A1 "I try to be courteous to everyone I meet", A10 "I generally try to be thoughtful and considerate", loaded positively and 08 "I believe we should look to our religious authorities for decision on moral
(C) 2014 www.ijip.in
July-September 2014
91 | P a g e 
The International Journal of Indian Psychology: Volume: 01 | Issue: 04 No. 2 | ISSN 2348-5396

issues", and O1 "I don't like to waste my time daydreaming" loaded negatively on Conscientiousness. The Neuroticism in the male sample has no these items, but in the female sample, A6 "I believe that most people will take advantage of you if you let them" loaded negatively. A4 "I would rather cooperate with others than compete with him" has positive loading only on male's Openness to Experience. A7 "most people I know like me" and N10 "I am seldom sad or depressed" in both samples with different sign, and in female sample, A4 "I rarely feel lonely or blue" loaded on the Extraversion. In the Agreeableness, E6 "I usually prefer to do things alone" placed in the both samples, and O11 "I have a lot of intellectual curiosity" and O12 "I often enjoy playing with theories or abstract ideas" loaded on the male sample.

\begin{tabular}{|c|c|c|c|c|c|}
\hline \multicolumn{6}{|c|}{$\begin{array}{l}\text { Table } 6 \\
\text { The items of Persian NEO-FFI were placed only on the factors }\end{array}$} \\
\hline sample & $\mathrm{N}$ & E & $\mathrm{O}$ & A & $\mathrm{C}$ \\
\hline Male & TM & N46, A33 & A19 & $\begin{array}{l}\text { O53, O58, } \\
\text { E27 }\end{array}$ & $\begin{array}{l}\text { E22, } \\
\text { O38, } \\
\mathbf{A 4 9}, \text { O3 }\end{array}$ \\
\hline Female & A29 & $\begin{array}{l}\text { N46, } \\
\text { N31 }\end{array}$ & & E27 a & $\begin{array}{l}\mathbf{E 2 2}, \quad \mathbf{O 2}, \\
\mathbf{0 3 8}, \quad \mathbf{A 4}, \\
\mathbf{A 4 9},\end{array}$ \\
\hline
\end{tabular}

Note. Boldface indicates items are loaded by both varimax and oblimin procedures.

\section{Confirmatory factor analysis}

Two CFA models were developed according to the results of present explanatory factor analysis for both groups (see Figure 2). Model A was developed based on the items belonged to their appropriate factors according to the NEO-FFI manual and extracted by the current PCA. These items are 37 for male and 41 for female samples. Model B was developed based on all of the items loadedon the factors extracted by PCA that was conducted in this study. Numbers of these items are 51 and 57 for male and female groups respectively. For specification of the latent variables of $\mathrm{N}, \mathrm{E}, \mathrm{O}, \mathrm{A}$, and $\mathrm{C}$, the loading for each latent variable's highest factor loading indicator was pre-set to 1.0 to create a metric scale. These items are N51, E37, O43, A14, and C15 for both groups.

The fit indexes for the hypothesized models are presented in Table 7. As can be seen in Table 7, the Model A fit the data relatively well for two groups, especially for male's. The chisquare was significant at $\mathrm{p}<.001$, but the relative chi-square for male's model was 1.99 and met
(C) 2014 www.ijip.in
July-September 2014
$92 \mid \mathrm{P}$ a g e 
The International Journal of Indian Psychology: Volume: 01 | Issue: 04 No. 2 | ISSN 2348-5396

the criteria for adequate fit $(<2.0)$ suggested by Byrne (1989). In the case of female's model A, this index exceeds the criteria (=2.5). The point estimate of RMSE A and its upper confidence limit were for both models was lower than .05 and indicate good fit as pointed out by (Hu and Bentler, 1999; Browne and Cudeck, 1993). The goodness-of- fit indexes for male group fit well and close to acceptable criteria $(\mathrm{GFI}=.88, \mathrm{IFI}=.91, \mathrm{CFI}=.91)$, and are better than female (GFI= $.82, \mathrm{IFI}=.88, \mathrm{CFI}=.88$ ). The models $\mathrm{B}$ for both groups don't fit the data well. The chi-squares are significant at $\mathrm{p}<.001$ and the relative chi-squares for both groups (2.44 for male and 2.81 for female) exceed the criteria. Although, the RMSEA is slightly below than .05, the goodness-of- fit indexes are inadequate.

Results of assessing items derived from the models including standardized solutions and squared multiple correlations $\left(\mathrm{R}^{2}\right)$ showed that all of the standardized solutions were significant with $t>2.0$, meaning these items significantly were reliable and correlated to the factor. But the $\mathrm{R}^{2}$ of itemsE2, O33, O58 in male's models and O33, A19, and A14 in female's model were low $\left(\mathrm{R}^{2}<0.1\right)$. This suggests that these items are not effective measures of their underlying factors.

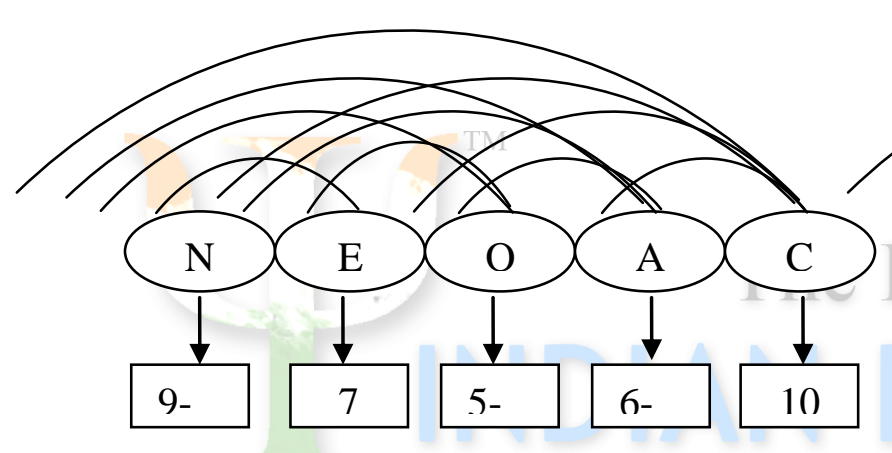

Model A

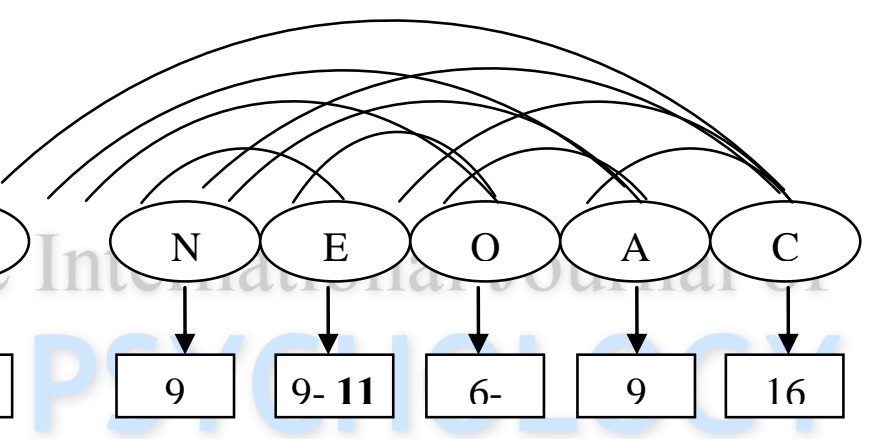

Model B

Figure 2. Path diagrams of models A and B of Persian NEO-FFI

Note. Digits in the squares indicate the number of items (indicators). Boldface indicates the number of items in female group. Model A included the items belonged to their appropriate factors, Model B included the items placed on the factors were extracted by present PCA.

\begin{tabular}{|c|c|c|c|c|c|c|c|}
\hline $\begin{array}{l}\text { Table } 7 \\
\text { The Goodr }\end{array}$ & it Statistic & CFA N & dels of & sian & -FFI & & \\
\hline Models & $\chi^{2}$ & $\mathrm{df}$ & $\chi^{2} / \mathrm{df}$ & GFI & IFI & CFI & RMSEA \\
\hline A & & & & & & & \\
\hline Male & $1235.1 * *$ & 619 & 1.99 & .88 & .91 & .91 & .042 \\
\hline Female & $1955.5 * *$ & 769 & 2.54 & .82 & .88 & .88 & .046 \\
\hline B & & & & & & & \\
\hline Male & $2963.8 * *$ & 1214 & 2.44 & .77 & .89 & .89 & .043 \\
\hline Female & $3843.3 * *$ & 1367 & 2.81 & .75 & .87 & .87 & .046 \\
\hline
\end{tabular}

Note. Model $\mathrm{A}=$ included the extracted items belonged to their appropriate factors (37 items male, 41 items female), Model $\mathrm{B}=$ included all of the items are loaded on the factors by the present PCA (51 items male, 57 items female). GFI=goodness of fit index, IFI= Incremental Fit 
The International Journal of Indian Psychology: Volume: 01 | Issue: 04 No. 2 | ISSN 2348-5396

Index, CFI=Comparative Fit Index, RMSEA=Root Mean Square Error of Approximation. $* * \mathrm{P}<.001$.

\section{Discussion}

The purpose of this study was to investigate the construct validity and factor structure of the Persian version of NEO-FFI, as a popular MFF instrument in the Persian speaking countries. Like the previous studies, we conducted the explanatory factor analysis through principle component analysis and tested two measurement models based on the confirmatory factor analysis to get clear understanding the Persian version NEO-FFI's factor structure.

First of all, the descriptive indices of the five factors indicated the distribution for Neuroticism positively skewed and for the next factors negatively skewed in both male and female samples. It seems the current participants tended to be present themselves in a favorable manner. While these results are similar with the findings reported by Aluja et al., (2005) in Spain and Switzerland, weren't replicated with the previous findings that indicated the positive skewness for N, O and C and negative for E and A (Holden and Fekken, 1994), the negative for A and C, and positive for the others (Panayiotou, Kokkinos and Spanoudis, 2004), and finally, the all factors have a normal and symmetrical distribution (Blackburn, Renwick, Donnelly and Logan, 2004).

The alpha Cronbach's coefficients of Neuroticism, Extraversion and Conscientiousness were relatively high, but theses coefficients for Openness and Agreeableness were lower than 0.7, the criteria assumed for the good internal consistency of subscales (Nunnally, 1978). The previous evidence has been found by many researchers (Parker and Stumpf, 1998; Rolland, Parker, and Stumpf, 1998; Sneed et al., 2002; Schmitz et al., 2000; Gignac, Bates and Jang, 2007; Panayiotou, and et al., 2004) showed these factors have some psychometric problems in different cultures in dicating the items of these scales are not homogenous.

While the results of the present factor analysis showed the best five factor solutions, it revealed some facts that were similar to the previous evidence. First, the variance explained by the five factors extracted was about $32 \%$ for both male and female samples and placed in the range of explained variances extracted by other researchers who reported between 27\% (Sneed et al., 2002) and about 37\% (Parker and Stumpf, 1998; Panayiotou, et al., 2004). Second, the factor structure of NEO-FFI in the item- level weren't replicated the scoring key in the manual. Based on oblimin procedures 8 and 3 items and based on the varimax procedure 10 and 7 items in the male and female samples respectively, had no loadings over than 0.30 in the five factors. Items of E6, E10, E12 and O4 were deleted in both samples. Furthermore, the items had loadings on their own factors were 37 and 41 of 60 items in male and female respectively. Similar finding have been found in previous studies (Sneed et al., 1998, Aluja et al., 2005, Panayiotou et al., 2004). Third, there was no notable difference in the NEO-FFI factor structure obtained by the oblique and orthogonal rotations especially in male sample. But in the female sample, the
(C) 2014 www.ijip.in
July-September 2014
$94 \mid \mathrm{P}$ a g e 
The International Journal of Indian Psychology: Volume: 01 | Issue: 04 No. 2 | ISSN 2348-5396

oblique rotation presented difference in the order of extracted factors and the missed items. While, the missed items in the oblique rotation were lesser than the orthogonal rotation, number of items which belonged to their appropriate factors were equal, excepted of N56 that was loaded by oblique rotation.

Regarding our main objective concerning the factor structure of Persian version NEOFFI, the results showed the first factorin both samples is $\mathrm{C}$, and it had more items (that belonged to their appropriate or the other factors) and emerged stronger than the other scales. But the order of next extracted factors was different in male and female groups based on the rotation procedures. In male sample, the order was $\mathrm{N}, \mathrm{E}, \mathrm{A}$ and $\mathrm{O}$ (in both procedures) and in female sample was $\mathrm{E}, \mathrm{N}, \mathrm{O}$, and $\mathrm{A}$, in varimax and $\mathrm{A}, \mathrm{E}, \mathrm{O}$ and $\mathrm{N}$ in oblimin procedures. Moreover, the female's factor structure seems to be clearer and stronger than male's one, especially based on the oblique rotation. Because the missed items in the later are lesser and the items loaded in their correspond factors are more than male's. Regarding the items were placed on appropriate factors, in the male group the Openness to Experience and the Agreeableness (whit 5 and 6 items respectively) were the weaker factors than the others. The Extraversion, in both groups, had 7 items and the Neuroticism had 9 items according to the inventory's scoring key. The number of cross-loaded items in the female group (13 items) was more than male group (11 items). But 6 items (N1, N21, E52, O53, C30, and C55) are cross -loaded in both.

These findings suggested that oblique rotation is slightly appropriate than varimax rotationto achieve more interpretable simple structure (as mentioned by Clarkson and Jennrich, 1988). Although, FFM theory may mandate that underlying latent constructs be uncorrelated with each other, the correlations between the underlying constructs are not assumed to be zero, and therefore the oblique rotation procedures may yield simpler and more interpretable factor patterns and will be more appropriate than orthogonal procedures.

The results of confirmatory factor analysis showed the hypothesized models based on the obtained factor structure have an unsatisfactory fit. In the other words, the models including both the items belonged to appropriate factors and the cross loading items did not fit the data well. But the models developed based on the items loaded only on the intended factors fit the data well, especially in male sample. These findings replicate the previous evidence that have shown CFA problems related to five factor model to reach acceptable levels of fit (Holden and Fekken, 1994;Schmitz et al., 2000;Panayiotou et al., 2004). But some researchers (Gignac et al., 2007) attributed these psychometric problems to the limitations and biasing of structural equating model.

An interesting result of current study is that the factor structure of (especially male's) Persian NEO-FFI was so similar with the findings that obtained by Panayiotouet al., (2004) who analyzed the instrument in the Greek context. The order of extracted factors in the two colures was the same. In addition, 31 items (of 41 items in Greek and of 37 items in Iranian men) that loaded on their appropriate factors were the same in two countries. The Extraversion and the Agreeableness had 7 and 8 items of 12 items in both cultures and 6 items of both factors were the same. In the case of factor $\mathrm{N}$, all of the 8 items of 12 items that loaded on Greek sample are 
The International Journal of Indian Psychology: Volume: 01 | Issue: 04 No. 2 | ISSN 2348-5396

common with Iranian one. The Conscientiousness had 11 and 10 items of 12 items in Greek and Iranian samples, respectively, and their difference belongs only to C45 that loaded on Greek group. The Openness to Experience had least items in both cultures (6 in Greek and 5 in Iranian samples) and their 5 items were alike. Comparing the cross-load items in the two samples, indicated that the items of A4, A49, and O8 placed in C, C30 loaded on N, N46 and A33 are loaded on $\mathrm{E}$, and $\mathrm{O} 58$ is placed on $\mathrm{A}$.

The other similarity of the two cultures addressed to the scales mean differences between men and women. As present results showed the Iranian men, like the Greek one, were significantly higher than women in the Extraversion. On the other hand, in the Neuroticism, Openness, and Agreeableness the Iranian women, as the Greek one, scored significantly higher than men. The only difference related to the Conscientiousness that in Iranian women was significantly higher than the men but there was no significant difference between Greek's men and women. These findings suggested a question that whether the people of the two oldest civilizations may be having common underlying cultural components that could be appeared in the personality traits!

As recommended by the previous studies, the NEO-FFI should be applied with serious caution. Because of the cultural differences that appeared in the traits conceptualization, many of the items could not be the appropriate indicators to measure the intended factors. Therefore, the personality researchers who want working with this personality instrument associated with unsatisfactory levels of EFA and CFA model-fit should consider the psychometrics problems and replacement the appropriate items from NEO-PI-R or add some items based on the cultural context to measure the factors adequately.

\section{References}

1. Ackerman, P. L., \&Heggestad, E. D. (1997).Intelligence, personality and interests: Evidence for overlapping traits, Psychological Bulletin, 121, 219-245.

2. Aluja, A., Garcia, O., Rossier, J., \&Garca, L. F. (2005).Comparison of the NEO-FFI, the NEO-FFI-R and an alternative short version of the NEO-PI-R (NEO-60) in Swiss and Spanish samples.Personality and Individual Differences, 38, 591-604.

3. Becker, G. (2006). NEO-FFI scores in college men and women: A view from McDonald's unified treatment of test theory. Journal of Research in Personality, 40, 911-941.

4. Berry, J. W. (1989). Imposed Etics-Emics-Derived Etics: The Operationalization of a Compelling Idea.International Journal of Psychology, 24, 721-735. 
The International Journal of Indian Psychology: Volume: 01 | Issue: 04 No. 2 | ISSN 2348-5396

5. Blackburn, R., Renwick, S. J. D., Donnelly, J. P., \&Logen, C. (2004).Big five or Big two? Superordinate factors in the NEO five factor inventory and the Antisocial Personality Questionnaire. Personality and Individual Differences, 37, 957-970.

6. Block, J. (1995). A contrarian view of the five-factor approach to personality description.Psychological Bulletin, 117, 187-215.

7. Borkenau, P., \&Ostendorf, F. (1989).Descriptive consistency and social desirability in self- and peer reports.European Journal of Personality, 3, 31-45.

8. Borkenau, P., \&Ostendorf, F. (1990).Comparing exploratory and confirmatory factor analysis: A study on the 5-factor model of personality.Personality and Individual Differences, $11,515-524$.

9. Borkenau, P., \&Ostendorf, F. (1993).NEO-Fünf-Faktoren-Inventar (NEO-FFI) nach Costa und McCrae [NEO-Five-Factor Inventory according to Costa and McCrae].Göttingen, Germany: Hogrefe

10. Brislin, R. W. (2000). Back-translation.In A. E. Kazdin (Ed.), Encyclopedia of psychology (Vol. 1, pp. 359-360). Washington, DC: American Psychological Association.

11. Browne, M. W., \&Cudeck, R. (1993) Alternative ways of assessing model fit. In K. A. Bollen\& J. S. Long (Eds.), Testing structural equation models (pp. 136-162) Newbury Park: Sage.

12. Byrne, B. M. (1989). Multigroup comparison and the assumptions of equivalent construct validity across group. Multivariate Behavioral Research, 23, 361-375.

13. Cattell, R. B. (1950). Personality: A systematic, theoretical, and factual study. New York: McGraw-Hill.

14. Clarkson, D.B., \&Jennrich, R.I. (1988).Quartic rotation criteria and algorithms.Psychometrica. 53, 251-259.

15. Costa, P. T., \& McCrae, R. R. (1992).NEO-PI-R Professional manual. Revised NEO Personality Inventory (NEO-PIR) and NEO Five Factor Inventory (NEO-FFI). Odessa, FL: Psychological Assessment Resources.

16. Deary, I. J., Blenkin, H., Agius, R. M., Endler, N. S., Zealley, H., \& Wood, R. (1996). Models of job-related stress and personal achievement among consultant doctors.British Journal of Psychology, 87, 3-29. 
The International Journal of Indian Psychology: Volume: 01 | Issue: 04 No. 2 | ISSN 2348-5396

17. Digman, J. M. (1990). Personality structure: the emergence of the five-factor model. In: M.R. Rosenzweig and L.W. Porter, Editors, Annual review of psychology Vol. 41, 417440.

18. Digman, J. M. (1997). Higher-Order Factors of the Big Five. Journal of Personality \& Social Psychology, 73, 1246-1256.

19. Egan, V., Deary, I., \& Austin, E. (2000). The NEO-FFI: emerging British norms and an item-level analysis suggests $\mathrm{N}, \mathrm{A}$, and $\mathrm{C}$ are more reliable than $\mathrm{O}$ and $\mathrm{E}$. Personality and Individual Differences, 29, 907-920.

20. Eysenck, H. J. (1992). Four ways five factors are not basic. Personality and Individual Differences, 13, 667-673.

21. Ferguson, E., \& Patterson, F. (1998). The Five factor model of personality: openness a distinct but related construct. Personality and Individual Differences, 24, 789-796.

22. Fink, B., Manning, J. T., \&Neave, N. (2004).Second to fourth digit ratio and the 'big five'personality factors.Personality and Individual Differences, 37, 495-503.

23. Gignac, G. E., Bates, T. C., \& Jang, K. L. (2007). Implications relevant to CFA model misfit, reliability, and the five-factor model as measured by the NEO-FFI. Personality and Individual Differences, 43, 1051-1062.

24. Goldberg, L.R. (1993).The Structure of Phenotypic Personality Traits.American Psychologist, 48, 26-34.

25. Gosling, S. D., Rentfrow, P. J., \& Swann, W. B. (2003).A very brief measure of the BigFive personality domains.Journal of Research in Personality, 37, 504-528.

26. Halim, S. M., Derksen, J. J. L., \& van der Staak, C. P. F (2004).Development of the revised NEO personality inventory for Indonesia: A preliminary study.In B. N. Setiadi, A. Supratiknya, W. J. Lonner, \& Y. H. Poortinga(Eds.). Ongoing themes in psychology and culture (Online Ed.). Melbourne, FL: International Association for Cross-Cultural Psychology.

27. Hofstede, G., \& McCrae, R. R. ( 2004). Personality and Culture Revisited: Linking Traits and Dimensions of Culture. Cross-Cultural Research, 38, 52-88.

28. Hofstee, W. K. (2003). Structures of personality traits.In T. Millon\& M. J. Lerner (Eds.), Personality and social psychology.Handbook of psychology (Vol. 5, pp. 231-254). Hoboken NJ: John Wiley \& Sons. 
The International Journal of Indian Psychology: Volume: 01 | Issue: 04 No. 2 | ISSN 2348-5396

29. Holden, R. R., \&Fekken, G. C. (1994).The NE0 Five-Factor Inventory in a Canadian Context: Psychometric Properties for a Sample of University Women. Personality and Individual Differences, 17, 441-444.

30. Hrebícková, M., Urbánek, T., Cermák, I., Szarota, P., Ficková, E., \&Orlická, L. (2002). The NEO Five-Factor Inventory in Czech, Polish, and Slovak contexts. In R. R. McCrae \& J. Allik (Eds.), The Five-Factor Model of personality across cultures (pp. 53-78). Dordrecht, Netherlands: Kluwer Academic Publishers.

31. Hu, L., \&Bentler, P. M. (1999). Cutoff criteria for fit indexes in covariance structure analysis: Conventional criteria versus new alternatives. Structural Equation Modeling, 6, $1-55$.

32. Huang, C. D., Church, A. T., \&Katigbak, M. S. (1997). Identifying cultural differences in items and traits: Differential item functioning in the NEO Personality Inventory.Journal of Cross-Cultural Psychology, 28, 192-218.

33. Hui,C. H., \& \& Triandis, H.C. (1985).Measurement in cross-cultural psychology.Areviewand comparison of strategies. Journal of Cross-cultural Psychology, $16,131-152$.

34. John, O. P., \&Srivastava, S. (1999). The Big Five trait taxonomy: History, measurement, and theoretical perspectives. In L. A. Pervin\& O. P. John (Eds).Handbook of personality: Theory and research (pp. 102-138).

35. Jöøreskog, K. G., \&Sörbom, D. (2003).LISREL (version 8.54).Scientific Software International, Inc.

36. McCrae, R. R., \& Costa, P. T. (1989).Rotation to maximize the construct validity of factors in the NEO PersonalityInventory. Multivariate Behavioral Research, 24, 107-124.

37. McCrae, R. R., \& Costa, P. T. Jr., (2004).A contemplated revision of the NEO FiveFactor Inventory.

38. McCrae, R.R., Costa, P.T., \& Busch, C.M. (1986).Evaluating comprehensiveness in personality systems: The California Q-set and the five-factor model. Journal of Personality and Social Psychology, 54, 430-446.

39. Nunnally JC Jr. 1978. Psychometric Theory (2nd edn). McGraw- Hill: New York. 
The International Journal of Indian Psychology: Volume: 01 | Issue: 04 No. 2 | ISSN 2348-5396

40. Panayiotou, G., Kokkinos, M. K., \&Spanoudis, S. (2004).Searching for the "Big Five"' in a Greek context: the NEO-FFI under the microscope. Personality and Individual Differences, 36, 1841-1854.

41. Parker, W. D., \&Stumpf, H. (1998).A validation of the five-factor model of personality in academically talented youth across observers and instruments.Personality and Individual Differences, 25, 1005-1025. Personality and Individual Differences, 36, 587-596.

42. Piedmont, R.L., McCrae, R.R., \& Costa, P.T. (1991).Adjective Check List scales and the five-factor model.Journal of Personality and Social Psychology, 60, 630-637.

43. Rolland, J. P., Parker, W. D., \&Stumpf, H. (1998). A psychometric examination of the French translations of theNEO-PI-R and NEO-FFI.Journal of Personality Assessment, 71, 269-291.

44. Saucier, G. (1994). Mini-Markers: A brief version of Goldberg's unipolar Big-Five markers. Journal of Personality Assessment, 63, 506-516.

45. Schmitz, N., Hartkamp, N., Baldini, C., Rollnik, J., \& Tress, W. (2001).Psychometric properties of the German version of the NEO-FFI in psychosomatic outpatients.Personality and Individual Differences, 31, 713-722.

46. Singelis, T. M., Yamada, A. M., Barrio, C., Laney Pa Her, J.H., Ruiz-Anaya, A., \&Lennertz, S.T. (2006). Metric Equivalence of the Bidimensional Acculturation Scale, the Satisfaction With Life Scale, and the Self-Construal Scale Across Spanish and English Language Versions, Hispanic Journal of Behavioral Sciences, 28, 231-244.

47. Sneed, C.D., Gullone, E., \& Moore, S. (2002). Reliability and Factor Structure of the NEO-Five-Factor Inventory for Australian Adolescents.Behavior Change, 19, 121-126.

48. Sneed, C.D., McCrae, R.R., \& Funder, D.C. (1998). Lay conceptions of the five-factor model and its indicators. Personality and Social Psychological Bulletin, 24, 115-126.

49. Spirrison, C. L., \& Choi, S. (1998). Psychometric Properties of a Korean Version of the Revised NEO-Personality Inventory. Psychological Reports, 83, 263-274.

50. Tokar, D. M., Fischer, A. R., Snell, A. F., \&Harik-Williams, N. (1999). Efficient assessment of the five-factor model of personality: Structural validity analyses of the NEO five-factor inventory (Form S). Measurement and Evaluation in Counseling and Development, 32, 14-30. 
51. vandeVijver, F. Jr., \& Leung, K. (1997). Methods and data analysis for cross- cultural research. Thousand Oaks, CA: Sage.

52. Welkenhuysen-Gybels, J., Billiet, J., \&Cambre, B. (2003).Adjustment for Acquiescence in the Assessment of the Construct Equivalence of Likert-Type Score Items.Journal of Cross-Cultural, 34, 702- 722.

53. Yoshimura, K., Ono, Y., Nakamura, K., Nathan, J. H., \& Suzuki, K. (2001).Validation of the Japanese version of the NEO-five factor inventory in a large community sample.Psychological Reports, 88, 443-449.
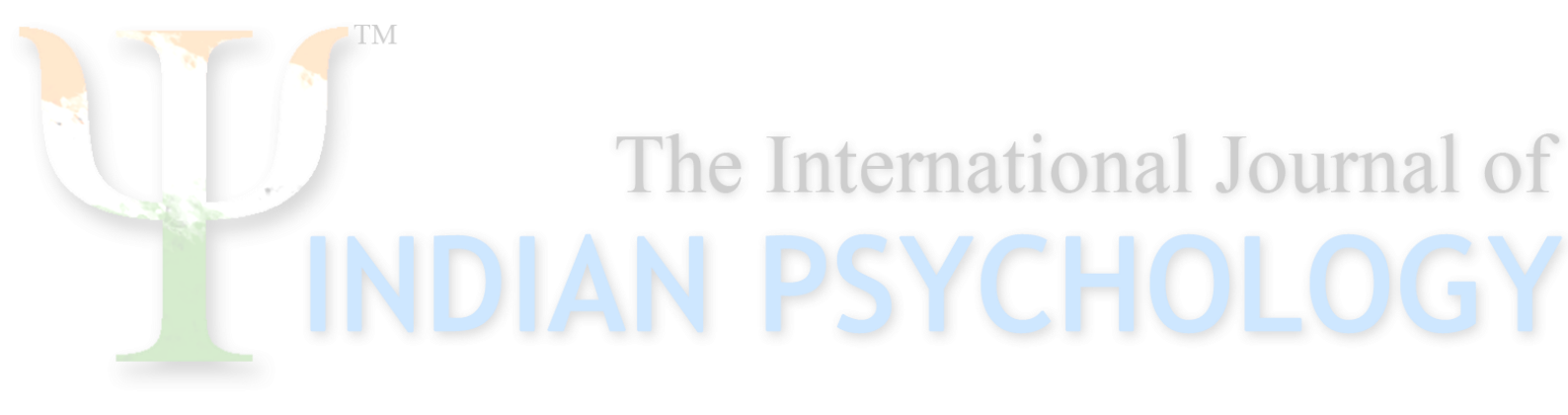